\title{
Identification of amino acids involved in histamine potentiation of $\mathrm{GABA}_{\mathrm{A}}$ receptors
}

\author{
Ulrike Thiel' ${ }^{1}$, Sarah J. Platt ${ }^{1}$, Steffen Wolf ${ }^{2,3}$, Hanns Hatt ${ }^{1}$ and Günter Gisselmann ${ }^{1 *}$ \\ ${ }^{1}$ Department of Cell Physiology, Ruhr University Bochum, Bochum, Germany, ${ }^{2}$ Department of Biophysics, Ruhr University \\ Bochum, Bochum, Germany, ${ }^{3}$ Department of Biophysics, Key Laboratory of Computational Biology, CAS-MPG Partner \\ Institute for Computational Biology, Shanghai Institutes for Biological Sciences, Chinese Academy of Sciences, Shanghai, \\ China
}

Histamine is a neurotransmitter involved in a number of physiological and neuronal functions. In mammals, such as humans, and rodents, the histaminergic neurons found in the tuberomamillary nucleus project widely throughout the central nervous system. Histamine acts as positive modulator of $\mathrm{GABA}_{A}$ receptors $\left(G A B A_{A} R s\right)$ and, in high concentrations $(10 \mathrm{mM})$, as negative modulator of the strychnine-sensitive

Edited by:

Jean-François Desaphy, University of Bari Aldo Moro, Italy

Reviewed by: Oscar Moran Consiglio Nazionale delle Ricerche,

Christoph Fahlke

Italy

Forschungszentrum Jülich, Germany

${ }^{*}$ Correspondence: Günter Gisselmann, Department of Cell Physiology, Ruhr University Bochum, Building

ND4-164, Universitätsstraße 150,

Bochum 44780, Germany guenter.gisselmann@rub.de

Specialty section:

This article was submitted to Pharmacology of lon Channels and Channelopathies, a section of the journal Frontiers in Pharmacology

Received: 19 February 2015 Accepted: 01 May 2015 Published: 26 May 2015

Citation:

Thiel U, Platt SJ, Wolf S, Hatt H and Gisselmann G (2015) Identification of amino acids involved in histamine potentiation of $G A B A_{A}$

receptors.

Front. Pharmacol. 6:106. doi: 10.3389/fphar.2015.00106 glycine receptor. However, the exact molecular mechanisms by which histamine acts on $\mathrm{GABA}_{A}$ Rs are unknown. In our study, we aimed to identify amino acids potentially involved in the modulatory effect of histamine on $G A B A_{A} R s$. We expressed $G A B A_{A} R s$ with 12 different point mutations in Xenopus laevis oocytes and characterized the effect of histamine on GABA-induced currents using the two-electrode voltage clamp technique. Our data demonstrate that the amino acid residues $\beta 2(N 265)$ and $\beta 2$ (M286), which are important for modulation by propofol, are not involved in the action of histamine. However, we found that histamine modulation is dependent on the amino acid residues $\alpha 1$ (R120), $\beta 2$ (Y157), $\beta 2$ (D163), $\beta 3(\mathrm{~V} 175)$, and $\beta 3(\mathrm{Q} 185)$. We showed that the amino acid residues $\beta 2(Y 157)$ and $\beta 3(Q 185)$ mediate the positive modulatory effect of histamine on GABA-induced currents, whereas $\alpha 1$ (R120) and $\beta 2$ (D163) form a potential histamine interaction site in $\mathrm{GABA}_{A} \mathrm{Rs}$.

Keywords: $\mathrm{GABA}_{A} R$, histamine, modulation, site-directed mutagenesis, potentiation, salt-bridge

\section{Introduction}

The $\mathrm{GABA}_{\mathrm{A}}$ receptor $\left(\mathrm{GABA}_{\mathrm{A}} \mathrm{R}\right)$ is the most important inhibitory receptor channel complex in the central nervous system (CNS). It is a pentameric ligand-gated ion channel, which is activated by $\gamma$-aminobutyric acid (GABA) and is modulated by various compounds. $\mathrm{GABA}_{\mathrm{A}} \mathrm{R}$ modulators include benzodiazepines, barbiturates, propofol, ethanol, neurosteroids, cations (e.g., zinc ions), herbal components and odorants as well as the neurotransmitter histamine (Bureau and Olsen, 1991; McDonald and Olsen, 1994; Thompson et al., 1996; Grobin et al., 1998; Hosie et al., 2003; Kim and McDonald, 2003; Belelli and Lambert, 2005; Li et al., 2006; Saras et al., 2008; Sergeeva et al., 2010; Rudolph and Knoflach, 2011; Kletke et al., 2013; Yip et al., 2013). Since 2008, it has been known that histamine could directly activate homomeric $\mathrm{GABA}_{\mathrm{A}}$ Rs composed of $\beta$ subunits and modulate the heteromeric GABA ${ }_{A}$ Rs $\alpha 1 \beta 2$ and $\alpha 1 \beta 2 \gamma 2$ (Saras et al., 2008). The modulatory effects of histamine on heteromeric $\mathrm{GABA}_{\mathrm{A}}$ Rs depend on the subunit composition of the receptors 
(Bianchi et al., 2011). Today, 19 subunits are known (Simon et al., 2004). These subunits are $\alpha 1-6, \beta 1-3, \gamma 1-3, \delta, \varepsilon, \theta, \pi$, and $\rho 1-3$. Bianchi et al. (2011) showed $\alpha$ subunit preference of histamine under low GABA concentrations.

Histamine is a neurotransmitter in the brain and a cytokine in the periphery. It is produced and released by mast cells, basophiles, enterochromaffin-like cells, and neurons (Haas et al., 2008). In the brain histamine is released from the tuberomammillary nucleus which is involved in the wakesleep regulation. Metabotropic histamine receptors $\left(\mathrm{H}_{1}-\mathrm{H}_{4}\right)$ mediate the physiological functions of histamine but at least three different types of neuronal ligand-gated ion channels are modulated by histamine (Bekkers, 1993; Saras et al., 2008; Bianchi et al., 2011; Kletke et al., 2013). The possible mechanism of the modulation of $\mathrm{GABA}_{\mathrm{A}} \mathrm{Rs}$ in the brain is still speculative (Saras et al., 2008; Bianchi et al., 2011).

Currently, the interaction site for histamine on the $\mathrm{GABA}_{\mathrm{A}} \mathrm{R}$ is unknown. There are many known modulation sites on the $\mathrm{GABA}_{\mathrm{A}} \mathrm{Rs}$ for various compounds. These sites include the amino acids $\beta 2(\mathrm{~N} 265)$ and $\beta 2(\mathrm{M} 286)$. These two amino acid residues are involved in the propofol and etomidate interaction with the $\mathrm{GABA}_{\mathrm{A}}$ Rs (Krasowski et al., 2001; Siegwart et al., 2002; Jurd et al., 2003; Reynolds et al., 2003). These amino acid residues represent some of the different modulation mechanisms of the receptor. Propofol and etomidate are positive modulators of the $\mathrm{GABA}_{\mathrm{A}}$ Rs. In addition to these described modulation sites, there are other identified sites of functional relevance. These sites are, e.g., the GABA-binding site, which involves the amino acid residue F64 of the $\alpha$ subunit and the amino acid residues Y157 and Y205 of the $\beta$ subunits (Sigel et al., 1992; Amin and Weiss, 1993). Recent studies with mutated amino acids V175, Q185, and D163 of the $\beta$ subunit and R120 of the $\alpha$ subunit, which are components of loop nine or are involved in a salt-bridge interaction, show that these amino acids are involved in stabilizing the closed state or involved in a state-dependent salt-bridge of the $\mathrm{GABA}_{\mathrm{A}}$ Rs (Williams et al., 2010; Laha and Wagner, 2011).

While binding sites on the $\mathrm{GABA}_{\mathrm{A}}$ Rs have already been described for some allosteric modulators, the molecular basis of

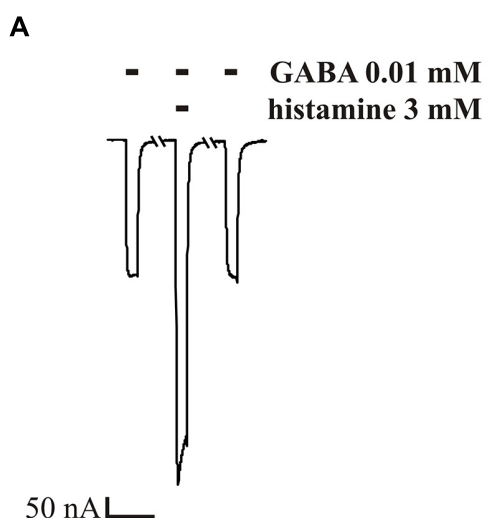

$60 \mathrm{~s}$

$\alpha 1 \beta 2 \gamma 2 L$

\section{C}

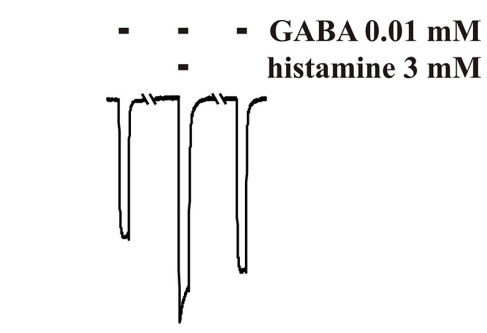

$100 \mathrm{nAL}$ $\alpha 2 \beta 3 \gamma 2 \mathrm{~L}$

FIGURE 1|GABA potentiated by histamine in wt receptors. GABA-induced $\left(E_{10-30}\right)$ currents are potentiated by $3 \mathrm{mM}$ histamine. (A-C) Xenopus oocytes expressing the abg isoforms: $\alpha 1 \beta 2 \gamma 2 \mathrm{~L}, \alpha 1 \beta 3 \gamma 2 \mathrm{~L}$, and $\alpha 2 \beta 3 \gamma 2 \mathrm{~L}$ were voltage clamped, and GABA at a concentration of $10 \mu \mathrm{M}$ was bath-applied with or without $3 \mathrm{mM}$ histamine. (D) Average

\section{B}

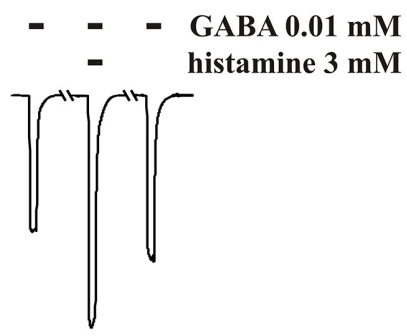

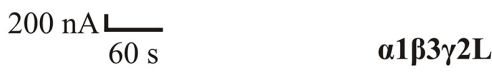

D

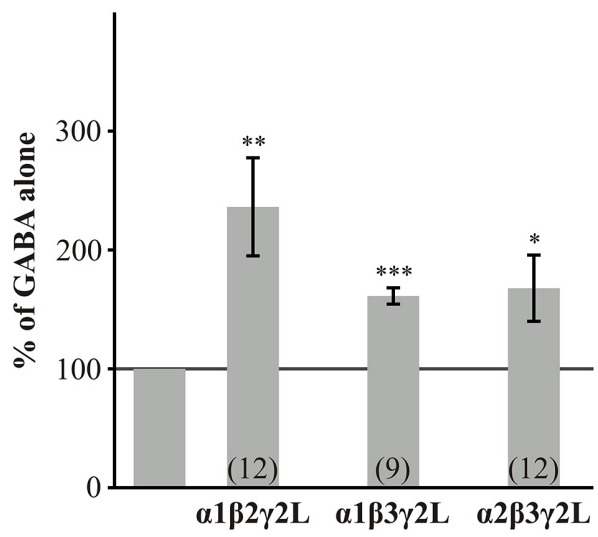

potentiation of GABA-induced currents calculated from measurements as shown in $(\mathbf{A}-\mathbf{C})$. Bars two to four show the mean enhancement \pm SEM, as a percentage of the amplitude of GABA alone (gray line), for the $\alpha \beta \gamma$ isoforms: $\alpha 1 \beta 2 \gamma 2 \mathrm{~L}, \alpha 1 \beta 3 \gamma 2 \mathrm{~L}$, and $\alpha 2 \beta 3 \gamma 2 \mathrm{~L}, \quad(n=9-12)$. Significant data were marked with ${ }^{*} p \leq 0.05,{ }^{* *} p \leq 0.01$, and ${ }^{* * *} p \leq 0.001$. 
A

$\alpha 1 \beta 2 \gamma 2 \mathrm{~L}$
$\alpha 1 \beta 2(\mathrm{~N} 265 \mathrm{M}) \gamma 2 \mathrm{~L}$
$\alpha 1 \beta 2(\mathrm{M} 286 \mathrm{~W}) \gamma 2 \mathrm{~L}$
$\alpha 1(\mathrm{~F} 64 \mathrm{~L}) \beta 2 \gamma 2 \mathrm{~L}$
$\alpha 1 \beta 2(\mathrm{Y} 157 \mathrm{~F}) \gamma 2 \mathrm{~L}$
$\alpha 1(\mathrm{~N} 185 \mathrm{~L}) \beta 2 \gamma 2 \mathrm{~L}$
$\alpha 1(\mathrm{L263S}) \beta 2 \gamma 2 \mathrm{~L}$
$\alpha 1 \beta 2(\mathrm{~L} 259 \mathrm{~S}) \gamma 2 \mathrm{~L}$
$\alpha 1(\mathrm{~L} 263 \mathrm{~S}) \beta 2(\mathrm{~L} 259 \mathrm{~S}) \gamma 2 \mathrm{~L}$
$\alpha 1(\mathrm{R} 120 \mathrm{~A}) \beta 2 \gamma 2 \mathrm{~L}$
$\alpha 1 \beta 2(\mathrm{D} 163 \mathrm{~A}) \gamma 2 \mathrm{~L}$
$\alpha 1(\mathrm{R} 120 \mathrm{~A}) \beta 2(\mathrm{D} 163 \mathrm{~A}) \gamma 2 \mathrm{~L}$

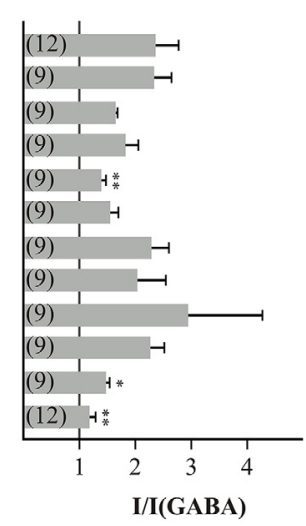

B

\section{$\alpha 2 \beta 3 \gamma 2 \mathrm{~L}$}

$\alpha 2 \beta 3(\mathrm{~V} 175 \mathrm{~A}) \gamma 2 \mathrm{~L}$

$\alpha 2 \beta 3(\mathrm{E} 182 \mathrm{~A}) \gamma 2 \mathrm{~L}$

$\alpha .2 \beta 3(\mathrm{Q} 185 \mathrm{~A}) \gamma 2 \mathrm{~L}$

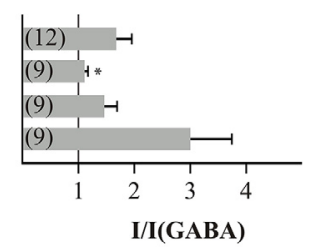

FIGURE 2 | Effect of $3 \mathrm{mM}$ histamine on the GABA-induced current of wt or mutated $\mathrm{GABA}_{\mathbf{A}} \mathbf{R s}$. The bars show the increase of the GABA-induced (typically $\mathrm{EC}_{10-30}$ ) currents by $3 \mathrm{mM}$ histamine of the $\mathrm{GABA}_{A} R$ subunit combination (A) $\alpha 1 \beta 2 \gamma 2 \mathrm{~L}$ and (B) $\alpha 2 \beta 3 \gamma 2 \mathrm{~L}$. Significant data were marked with ${ }^{*} p \leq 0.05$ and ${ }^{* *} p \leq 0.01$.

positive allosteric receptor modulation by histamine is unknown. Therefore, we plan to identify the amino acids that are involved in the modulatory effect of histamine at the $G_{A B A}$ Rs. For that purpose, we investigated site-directed mutated $\mathrm{GABA}_{\mathrm{A}} \mathrm{Rs}$ expressed in a Xenopus laevis expression system using the twoelectrode voltage clamp technique, and analyzed the structural impact of the chosen amino acids by creating a homology model of a $2 \mathrm{x} \alpha 1-3 \mathrm{x} \beta 3 \mathrm{GABA}_{\mathrm{A}}$ Rs heteropentamer.

\section{Materials and Methods}

\section{GABA $_{A} R$ cDNA}

Expression plasmids based on the pSGEM vector (courtesy of M. Hollmann, Bochum, Germany) for rat $\alpha 1, \beta 2$, mouse $\gamma 2 \mathrm{~L}$, and human $\beta 3$ were described by Saras et al. (2008). Rat $\alpha 2$ cDNA was kindly provided by ImaGenes, Berlin, Germany, and subcloned into pSGEM by using PCR and standard molecular biology methods.

The point mutations were made using overlap-extension PCRs, as described by Heckman and Pease (2007). For overlapextension PCRs, the plasmids for $\alpha 1, \beta 2$, and $\beta 3$ subunits were used as templates. Overlap-extension PCR was performed using a mixture of taq-DNA- and pwo-DNA-polymerase (20:1) (Biotherm) in a volume of $50 \mu \mathrm{l}$ with $20 \mathrm{pmol}$ of each primer (Supplementary Table S3). The following temperature cycle profile was used: $5 \mathrm{~min}$ at $95^{\circ} \mathrm{C}$; followed by 30 cycles of $45 \mathrm{~s}$ at $95^{\circ} \mathrm{C}, 45 \mathrm{~s}$ at $60^{\circ} \mathrm{C}, 60 \mathrm{~s}$ at $72^{\circ} \mathrm{C}(120 \mathrm{~s}$ for the fusion PCR); and a final extension of $10 \mathrm{~min}$ at $72^{\circ} \mathrm{C}$. The mutated DNA was subcloned into pSGEM using standard molecular biology methods.

\section{Expression of Receptor cRNA in Xenopus laevis oocytes}

The cRNAs of wt as well as point mutated $\mathrm{GABA}_{\mathrm{A}} \mathrm{R}$ subunit cRNAs were synthesized by using the AmpliCap T7 high yield message maker kit (Epicentre, Madison, WI, USA) as described by Sergeeva et al. (2010). The oocytes were prepared from Xenopus laevis using standard methods. Five to twenty nanograms of cRNA was injected, $24 \mathrm{~h}$ after surgery, into one stage $\mathrm{V}-\mathrm{VI}$ oocyte. The incubation took place at 12$16^{\circ} \mathrm{C}$ in $\mathrm{ND} 96$ [96 $\mathrm{mM} \mathrm{NaCl}, 2 \mathrm{mM} \mathrm{KCl}, 1.8 \mathrm{mM} \mathrm{CaCl}_{2}$, $1 \mathrm{mM} \mathrm{MgCl} 2,5 \mathrm{mM}$ HEPES, $\mathrm{pH} 7.2 ; 100 \mathrm{U} / \mathrm{ml}$ penicillin, $100 \mathrm{U} / \mathrm{ml}$ streptomycin from Antibiotic Antimycotic Solution $(100 \mathrm{x})$ ] (Sigma-Aldrich, St. Louis, MO, USA). After 2-4 days, the oocytes were measured by two-electrode voltage clamp, as briefly described by Sergeeva et al. (2010). Each of the tested substances was diluted with Frog-Ringer's solution $(115 \mathrm{mM}$ $\mathrm{NaCl}, 2.5 \mathrm{mM} \mathrm{KCl}, 1.8 \mathrm{mM} \mathrm{CaCl}, 10 \mathrm{mM}$ HEPES, $\mathrm{pH}$ 7.2). The agonists were dissolved in ND96 and applied in a volume of $200 \mu \mathrm{l}$ into the entrance tube of the recording chamber, totally exchanging the bath solution within a second. Therefore, due to the relative slow desensitization kinetics in our investigated GABA receptors and the fact that we compare the same receptor \pm histamine, desensitization will not interfere with the determination of the histamine potentiation. The $\mathrm{pH}$ of GABA- or histamine-containing solutions was monitored to ensure a $\mathrm{pH}$ of 7.2 for all histamine concentrations. All measurements were taken with a membrane potential of $-40 \mathrm{mV}$.

\section{Analysis and Statistics}

During the measurements, the currents were recorded using CellWorks software and were analyzed using pCLAMP 10 software. The statistical evaluation and curve fitting (3-parameter Hill equation) was performed using SigmaPlot V8.0 (Systat Software, San Jose, CA, USA). All mean values are \pm SEM, and the significant data were marked with ${ }^{*} p \leq 0.05,{ }^{* *} p \leq 0.01$, and *** $p \leq 0.001$.

\section{$\mathrm{GABA}_{\mathrm{A}} \mathrm{R}$ Homology Modeling and Histamine Docking}

The $2.97 \AA$ crystal structure of the GABA $\beta 3$ homopentamer (Miller and Aricescu, 2014) was used as basis for homology modeling. We carried out a sequence alignment of the $\alpha 1$ sequence (Uniprot entry P14867, The UniProt Consortium, 2013) and the $\beta 3$ subunit sequences from the crystal structure with MUSCLE (Edgar, 2004; default settings). The resulting alignment showed $35.3 \%$ sequence identity and $61.9 \%$ sequence similarity and is included in the Supplementary Material. As we know from GPCR modeling, an identity $>35 \%$ is a good basis for homology modeling of transmembrane proteins (Wolf et al., 2008; Kufareva et al., 2011). Based on this alignment, we created and optimized a model of an $\alpha 1$ subunit homopentamer with the SWISS-MODEL server (Biasini et al., 2014), based on the 
A

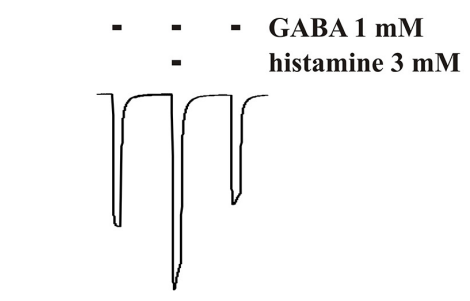

$500 \mathrm{nA} \underset{60 \mathrm{~s}}{ }$

$\alpha 1 \beta 2(Y 157 F) \gamma 2 L$

B

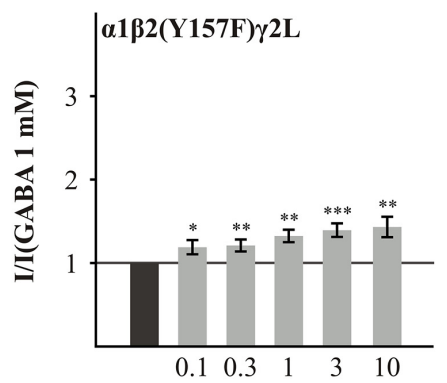

- GABA 1 mM

- GABA $1 \mathrm{mM}$ and histamine $[\mathrm{mM}]$

C

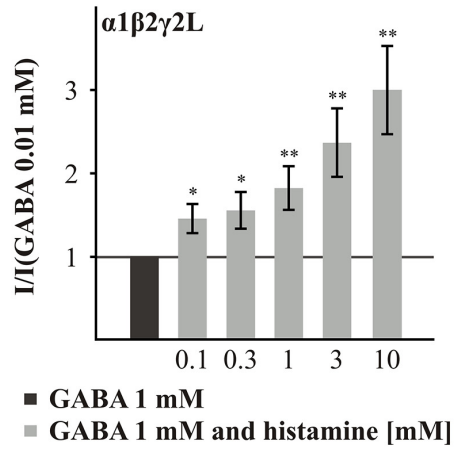

FIGURE 3 | Histamine action on GABA-induced currents of GABA $_{A}$ Rs with the point mutated $\beta 2(Y 157 F)$ subunit. (A,D) Original traces of the histamine $(3 \mathrm{mM})$ action on the GABA-induced currents of the $\mathrm{GABA}_{A} R \mathrm{Rs}$ a132(Y157F) $\gamma 2 \mathrm{~L}$ and $\alpha 1 \beta 2(Y 157 F)$. (B,C,E,F) Bar diagrams show the

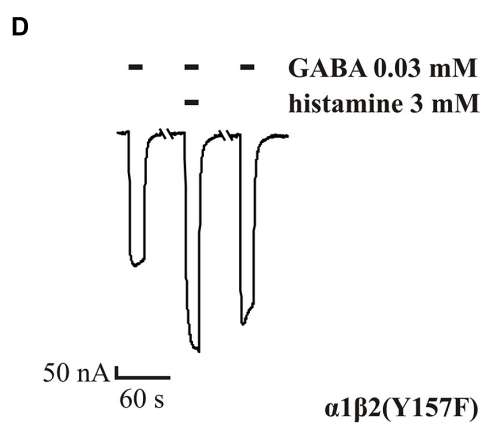

E

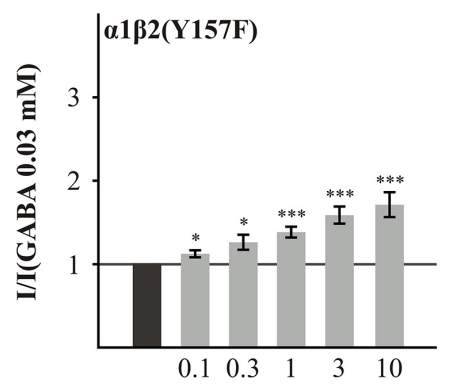

- GABA $0.03 \mathrm{mM}$

- GABA $0.03 \mathrm{mM}$ and histamine [mM]

$\mathbf{F}$

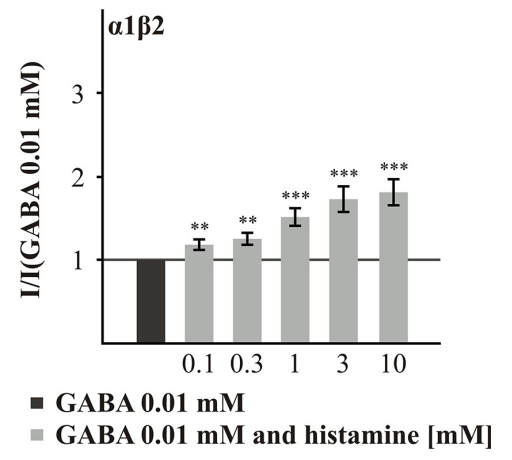

action of various histamine concentrations on the GABA-induced currents of the $\mathrm{GABA}_{A} \mathrm{Rs} \alpha 1 \beta 2(\mathrm{Y} 157 \mathrm{~F}) \gamma 2 \mathrm{~L}, \alpha 1 \beta 2(\mathrm{Y} 157 \mathrm{~F}), \alpha 1 \beta 2 \gamma 2 \mathrm{~L}$, and $\alpha 1 \beta 2$.

Significant data were marked with ${ }^{*} p \leq 0.05,{ }^{* *} p \leq 0.01$, and *** $p \leq 0.001$ structure of the $\beta 3$ homopentamer from the crystal structure mentioned above. We then created a $2 \mathrm{x} \alpha 1-3 \mathrm{x} \beta 3 \mathrm{GABA}_{\mathrm{A}} \mathrm{R}$ heteropentamer by substituting two $\beta 3$ subunits in the crystal structure (chain A and C) by the respective $\alpha 1$ subunits in PyMol (Schrödinger, 2010). We then carried out a WHATIF protein check, showing that the model is reliable. The checkfile can be found in the Supplementary Material. Binding site analysis was carried out with TRIDOCK (te Heesen et al., 2007). In short, TRIDOCK searches for putative binding positions for small organic molecules following Congreve's rule-of-three
(Congreve et al., 2003) and marks these positions with a "bead." Docking calculations on histamine binding were carried out with Autodock Vina (Trott and Olson, 2010), using a $20 \times 20 \times 20 \AA$ box (grid spacing $1 \AA$ ) centered between Asp163( $\beta)$ and R120( $\alpha$ ), and an exhaustiveness parameter of 80 (Schneider et al., 2011). A histamine topology was obtained from the PRODRG server (Schuttelkopf and van Aalten, 2004). Polar atoms and Kollman charges were added to the heteropentameric protein, while histamine was docked with Gasteiger charges. 
A

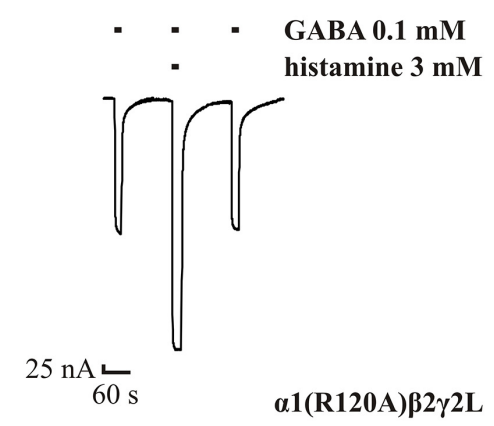

B

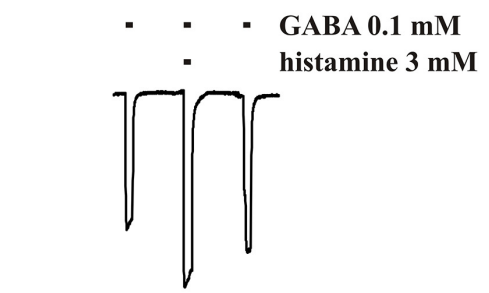

25 nAL

$60 \mathrm{~s}$

$\alpha 1 \beta 2(D 163 A) \gamma 2 L$

C

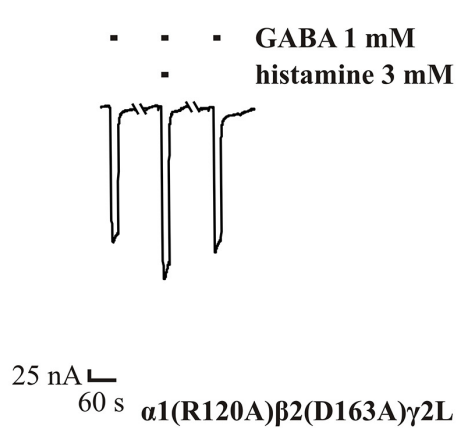

FIGURE 4 | Histamine action on GABA-induced currents of GABA $A$ Rs with point mutated subunits $\alpha 1$ (R120A) and $\beta 2$ (D163A). (A-C) Original traces of the modulatory effect of $3 \mathrm{mM}$ histamine on GABA-induced currents from $\mathrm{GABA}_{A} \mathrm{Rs} \alpha 1(\mathrm{R} 12 \mathrm{AA}) \beta 2 \gamma 2 \mathrm{~L}, \alpha 1 \beta 2(\mathrm{D} 163 \mathrm{~A}) \gamma 2 \mathrm{~L}$, and
D

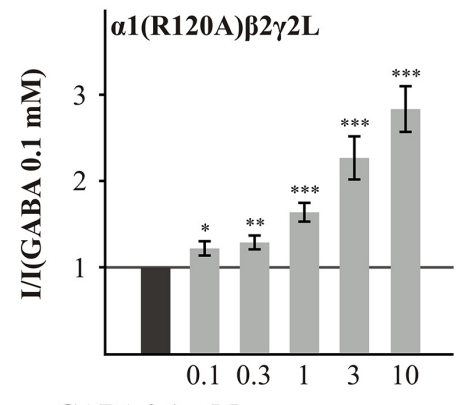

- GABA 0.1 mM

GABA $0.1 \mathrm{mM}$ and histamine $[\mathrm{mM}]$

E

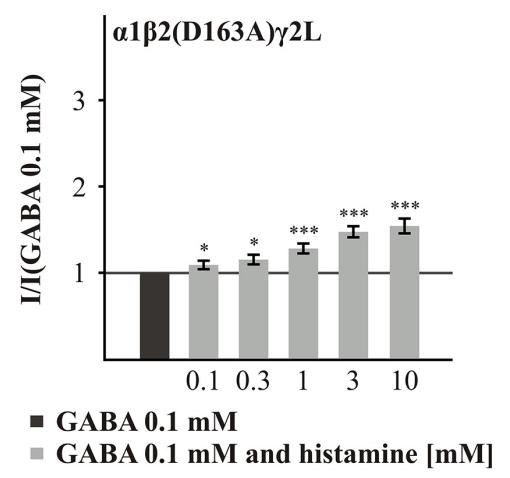

$\mathbf{F}$

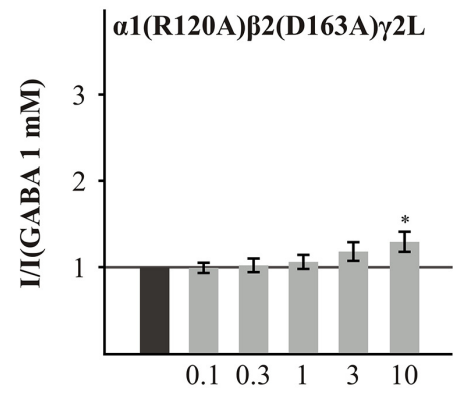

- GABA 1 mM

- GABA $1 \mathrm{mM}$ and histamine $[\mathrm{mM}]$

$\alpha 1(R 120 A) \beta 2(D 163 A) \gamma 2 L$. (D-F) Bar diagrams show the effect of 0.1 to $10 \mathrm{mM}$ histamine on the GABA-induced (typically $\mathrm{EC}_{10-30}$ ) current. Significant data were marked with $* p \leq 0.05,{ }^{* *} p \leq 0.01$, and ${ }^{* * *} p \leq 0.001$

\section{Results}

\section{Screening of Mutated GABA ${ }_{A}$ Rs for Altered Histamine Potentiation}

Saras et al. (2008) showed that homomeric $\beta 2$ or $\beta 3$ receptors were activated by histamine in a recombinant expression system.
Our intention was to analyze the effect of histamine on point mutated $\mathrm{GABA}_{\mathrm{A}} \mathrm{R} \beta 2 / 3$ subunits. First, we generated mutations in $\beta 2 / 3$ subunits. In contrast to the wild-type (wt) subunits, functional expression of mutated $\mathrm{GABA}_{\mathrm{A}} \mathrm{Rs}$ as homomeric receptors failed in most instances so that a systematic screening of homomeric receptors was not possible. Therefore, we had to 
A

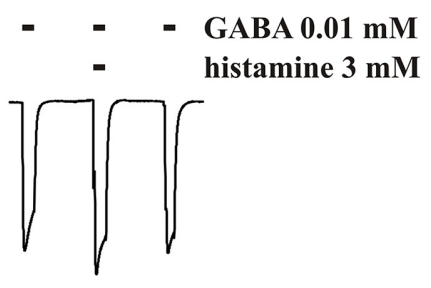

$100 \mathrm{nA} \underset{60 \mathrm{~s}}{\mathbf{6}}$

$\alpha 2 \beta 3(V 175 A) \gamma 2 L$

B

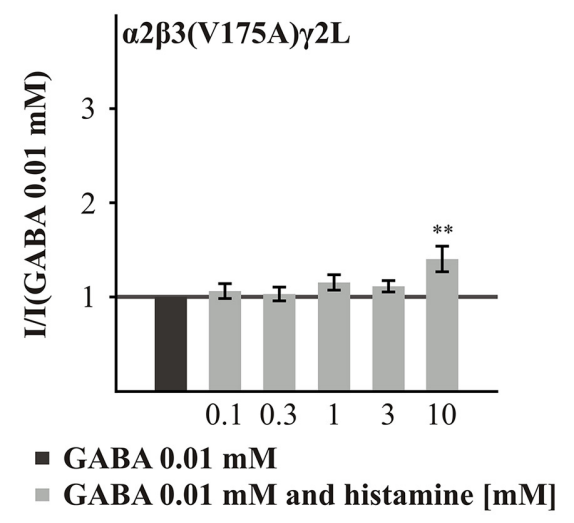

FIGURE 5 | Histamine action on the GABA-induced currents of $\mathrm{GABA}_{\mathbf{A}}$ Rs with point mutated $\beta 3(\mathrm{~V} 175 \mathrm{~A})$. (A) Original trace of the effect of $3 \mathrm{mM}$ histamine on the GABA-induced currents of the GABA $A_{A} R$ $\alpha 2 \beta 3(\mathrm{~V} 175 \mathrm{~A}) \gamma_{2} \mathrm{~L}$. (B) Bar diagram show the effect of various histamine concentrations up to $10 \mathrm{mM}$ on the GABA-induced currents of the $\mathrm{GABA}_{A} R$ $\alpha 2 \beta 3(\mathrm{~V} 175 \mathrm{~A}) \gamma 2 \mathrm{~L}$. Significant data were marked with ${ }^{* *} p \leq 0.01$.

determine the impact of mutated amino acids in heteromeric receptors by analyzing the potentiating effect of histamine on the GABA-induced currents. We were mostly interested in the effect of histamine on the two most important synaptic $\mathrm{GABA}_{\mathrm{A}}$ Rs of the CNS composed of $\alpha 1 \beta 2 \gamma 2 \mathrm{~L}$ and $\alpha 2 \beta 3 \gamma 2 \mathrm{~L}$ subunits (Pirker et al., 2000; Nutt, 2006; Olsen and Sieghart, 2008).

To screen the modulating effect of histamine, we investigated the action of $3 \mathrm{mM}$ histamine on currents evoked by GABA (typically $\mathrm{EC}_{10-30}$ ). To determine suitable GABA concentrations for screening experiments, the $\mathrm{EC}_{50}$ values of $\mathrm{GABA}$ for all of the investigated subunit combinations were determined (Supplementary Table S1). In addition, we tested histamine concentrations up to $10 \mathrm{mM}$ to demonstrate the absence of homomeric $\mathrm{GABA}_{\mathrm{A}}$ Rs composed of $\beta$ subunits. For all of our analyzed $\mathrm{GABA}_{\mathrm{A}} \mathrm{Rs}$, histamine alone did not induce any currents (data not shown).

First, we analyzed the wt $\mathrm{GABA}_{\mathrm{A}} \mathrm{Rs} \alpha 1 \beta 2 \gamma 2 \mathrm{~L}, \alpha 1 \beta 3 \gamma 2 \mathrm{~L}$, and $\alpha 2 \beta 3 \gamma 2 \mathrm{~L}$, to demonstrate a robust and reproducible potentiation of GABA-induced currents by histamine under our experimental conditions. This analysis also served as control for our experiments with the point mutated $\mathrm{GABA}_{\mathrm{A}}$ Rs. With our experiments, we could show, as Saras et al. (2008) had previously, that histamine could increase the GABA-induced current of wt receptors in a dose-dependent manner. Three millimolar histamine significantly potentiated the GABA-induced currents of $\mathrm{GABA}_{\mathrm{A}}$ Rs $\alpha 1 \beta 2 \gamma 2 \mathrm{~L}$ by approximately 1.4 -fold, $\alpha 1 \beta 3 \gamma 2 \mathrm{~L}$ by approximately 0.6 -fold and $\alpha 2 \beta 3 \gamma 2 \mathrm{~L}$ by approximately 0.7 -fold (Figure 1).

Next, we screened all point mutated $G_{A B A}$ Rs using the same conditions: a GABA concentration of typical $\mathrm{EC}_{10-30}$ and a histamine concentration of $3 \mathrm{mM}$. The first amino acids to be analyzed for their action in the histamine modulation of the $\mathrm{GABA}_{\mathrm{A}} \mathrm{R}$ were the point mutants $\beta(\mathrm{N} 265 \mathrm{M})$ and $\beta(\mathrm{M} 286 \mathrm{~W})$. These amino acids are involved in the action of etomidate and propofol on the $\mathrm{GABA}_{\mathrm{A}} \mathrm{Rs}$ (Krasowski et al., 2001; Siegwart et al., 2002; Jurd et al., 2003; Reynolds et al., 2003). Our experiments showed that the GABA-induced currents $\left(10 \mu \mathrm{M}\right.$ GABA) on $\mathrm{GABA}_{\mathrm{A}}$ Rs that contained the point mutated subunits $\beta(\mathrm{N} 265 \mathrm{M})$ or $\beta(\mathrm{M} 286 \mathrm{~W})$ were increased by histamine (Figure 2). However, the histamine modulation of the mutated receptors was not significantly different from the modulation of the wt $\mathrm{GABA}_{\mathrm{A}} \mathrm{Rs} \alpha 1 \beta 2 \gamma 2 \mathrm{~L}$. Therefore, these mutations do not influence histamine modulation.

The next 10 amino acids that we analyzed are important for binding GABA, for forming a state-dependent salt-bridge or for stabilizing the closed state of the $\mathrm{GABA}_{\mathrm{A}} \mathrm{Rs}$ (Amin and Weiss, 1993; Williams et al., 2010; Laha and Wagner, 2011). Furthermore, we were interested in the influence of the conserved leucine in the pore-forming TM2 segment that is involved in the gating-mechanism of the $\mathrm{GABA}_{\mathrm{A}} \mathrm{Rs}$ (Chang and Weiss, 1999 ). Because this amino acid, $\beta 2$ (L259), is also present in $\alpha$ subunits, we investigated point mutations of both a and $\beta$ subunits. Receptors with the mutations $\beta 2(\mathrm{Y} 157 \mathrm{~F}), \beta 2(\mathrm{D} 163 \mathrm{~A})$, $\beta 3(\mathrm{~V} 175 \mathrm{~A})$, and the combination of $\alpha 1(\mathrm{R} 120 \mathrm{~A})$ with $\beta 2(\mathrm{D} 163 \mathrm{~A})$ showed significantly reduced potentiation of the GABA-induced current by histamine (Figure 2).

It can be suggested that the amino acids Y157, D163, and V175 of the $\beta$ subunit and the amino acid R120 of the $\alpha$ subunit are involved in the action of histamine. The analyzed $\mathrm{GABA}_{\mathrm{A}} \mathrm{R}$ $\alpha 2 \beta 3(\mathrm{Q} 185 \mathrm{~A}) \gamma 2 \mathrm{~L}$ showed a stronger potentiation than the wt demonstrating that the amino acid Q185 also potentially affects histamine action on $\mathrm{GABA}_{\mathrm{A}}$ Rs.

\section{Dose-Dependent Action of Histamine on Mutated GABA $A_{A}$ Rs}

To investigate the impact of the identified amino acids on histamine modulation in more detail, we next analyzed the effect of different histamine concentrations $(0.1$ to $10 \mathrm{mM})$ on the GABA-induced current (typically $\mathrm{EC}_{10-30}$ ).

The first amino acid residue we analyzed was Y157 of the $\beta$ subunit. This amino acid residue is involved in the conformational changes in the $\mathrm{GABA}_{\mathrm{A}} \mathrm{Rs}$ induced by GABA (Amin and Weiss, 1993). GABA ${ }_{A} R \alpha 1 \beta 2(Y 157 F) \gamma 2 L$ showed reduced potentiation of the GABA-induced current by $3 \mathrm{mM}$ histamine (Figure 2A) in comparison to the wt $\alpha 1 \beta 2 \gamma 2 \mathrm{~L}$ receptor. Histamine concentrations of 0.1 to $10 \mathrm{mM}$ potentiated the GABA-induced current in a dose-dependent manner 
A

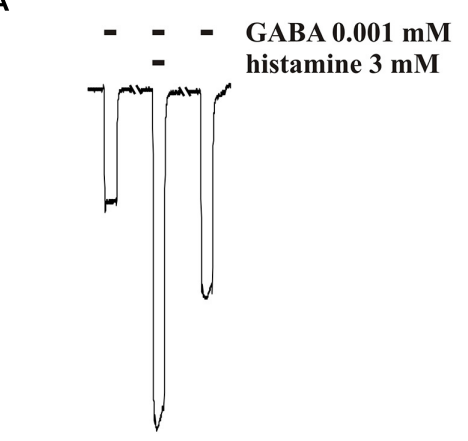

$50 \mathrm{nAL} \frac{\mathrm{Ls}}{60 \mathrm{~s}}$

$\alpha 2 \beta 3(\mathrm{Q} 185 \mathrm{~A}) \gamma 2 \mathrm{~L}$

B

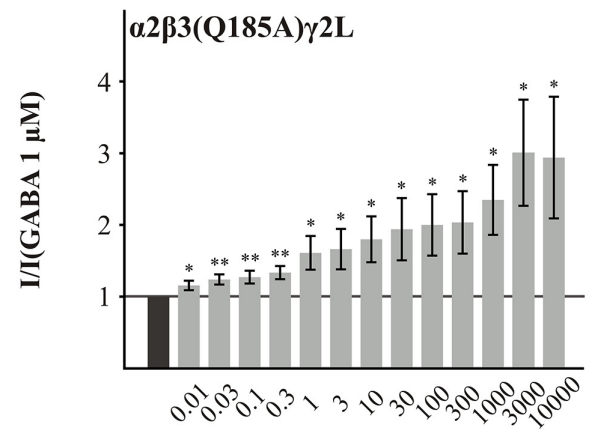

- GABA $1 \mu M$

- GABA $1 \mu \mathrm{M}$ and histamine $[\mu \mathrm{M}]$

C

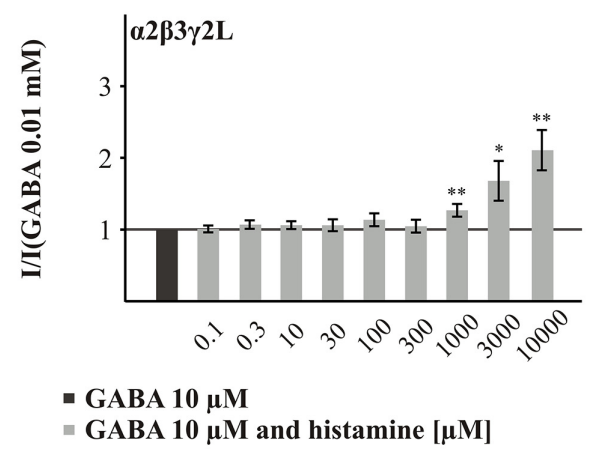

FIGURE 6 | Histamine action on the GABA-induced currents of GABA $_{A}$ Rs with the point mutated $\beta 3\left(Q_{1} 185 A\right)$ subunit. (A) Original trace of the histamine $(3 \mathrm{mM})$ action on the GABA-induced $\left(\mathrm{EC}_{11}\right)$ currents of the $\mathrm{GABA}_{A} R \alpha 2 \beta 3(\mathrm{Q} 185 \mathrm{~A}) \gamma 2 \mathrm{~L}$. (B,C) Bar diagrams that show the action of different histamine concentrations on the GABA-induced currents of the $\mathrm{GABA}_{\mathrm{A}} \mathrm{Rs} \alpha 2 \beta 3(\mathrm{Q} 185 \mathrm{~A}) \gamma 2 \mathrm{~L}$ and $\alpha 2 \beta 3 \gamma 2 \mathrm{~L}$. Significant data were marked with $* p \leq 0.05$ and $* * 0.01$.

(Figures 3A,B). However, for all of the tested concentrations, the potentiating effect was smaller than the effect observed with the wt receptor (Figures 3B,C, and Supplementary Table S2). To analyze the influence of the $\gamma 2 \mathrm{~L}$ subunit, we co-expressed the subunits $\alpha 1$ and $\beta 2(\mathrm{Y} 157 \mathrm{~F})$. Histamine caused a dosedependent potentiation of the mutated $\mathrm{GABA}_{\mathrm{A}} \mathrm{R}$ (Figures 3D,E) that was not significantly different from the wt $\alpha 1 \beta 2$ receptor (Figures 3E,F, and Supplementary Table S2). Interestingly, the influence of the point mutations is dependent on the presence of the $\gamma 2 \mathrm{~L}$ subunit. These results show that $\mathrm{Y} 157$ is not essential for potentiation by histamine.

Next, we analyzed the effect of histamine on the amino acids $\alpha 1(\mathrm{R} 120)$ and $\beta 2$ (D163), which form a state-dependent salt-bridge of the $\mathrm{GABA}_{\mathrm{A}} \mathrm{Rs}$ (Laha and Wagner, 2011). We investigated the ability of different histamine concentrations ( 0.1 to $10 \mathrm{mM}$ ) to potentiate the $\mathrm{GABA}$ response (typically $\mathrm{EC}_{10-30}$ ) on the $\mathrm{GABA}_{\mathrm{A}} \mathrm{Rs} \alpha 1(\mathrm{R} 120 \mathrm{~A}) \beta 2 \gamma 2 \mathrm{~L}, \alpha 1 \beta 2(\mathrm{D} 163 \mathrm{~A}) \gamma 2 \mathrm{~L}$, and $\alpha 1(\mathrm{R} 120 \mathrm{~A}) \beta 2(\mathrm{D} 163 \mathrm{~A}) \gamma 2 \mathrm{~L}$ (Figure 4). Histamine shows a dosedependent potentiation on the GABA $\mathrm{Rs} \alpha 1(\mathrm{R} 120 \mathrm{~A}) \beta 2 \gamma 2 \mathrm{~L}$ and $\alpha 1 \beta 2(D 163 A) \gamma 2 L$ (Figures 4A,B,D,E). However, at a receptor composed of both mutated subunits in combination with the $\gamma 2 \mathrm{~L}$ subunit, the increasing effect of histamine is nearly abolished (Figures 4C,F). In comparison to wt, the mutation $\alpha 1(\mathrm{R} 120 \mathrm{~A})$ alone had no significant effect on histamine potentiation (Supplementary Table S2). At GABA ${ }_{\mathrm{A}}$ Rs $\alpha 1 \beta 2(\mathrm{D} 163 \mathrm{~A}) \gamma 2 \mathrm{~L}$ and $\mathrm{GABA}_{\mathrm{A}} \mathrm{R} \alpha 1(\mathrm{R} 120 \mathrm{~A}) \beta 2(\mathrm{D} 163 \mathrm{~A}) \gamma 2 \mathrm{~L}$ (Figure 3C), histamine potentiation was significantly less than at the wt for most concentrations tested (Supplementary Table S2). To ensure that this effect is specific to histamine and does not abolish potentiation in general, we tested the potentiation of the GABAinduced currents by $10 \mu \mathrm{M}$ propofol (Yip et al., 2013), which was able to potentiate the GABA-induced current (data not shown). To verify the influence of the $\gamma 2 \mathrm{~L}$ subunit, we attempted to express the subunit combinations $\alpha 1(\mathrm{R} 120 \mathrm{~A}) \beta 2, \alpha 1 \beta 2(\mathrm{D} 163 \mathrm{~A})$, and $\alpha 1(\mathrm{R} 120 \mathrm{~A}) \beta 2(\mathrm{D} 163 \mathrm{~A})$, but none of these combinations produced a functional receptor.

The last two amino acids that we analyzed were V175 and Q185 on the $\beta$ subunit. These amino acids are located in loop 9, which is in close proximity to the salt-bridge formed by $\alpha 1(\mathrm{R} 120 \mathrm{~A})$ and $\beta 2(\mathrm{D} 163 \mathrm{~A})$. The experiments with the $\mathrm{GABA}_{\mathrm{A}} \mathrm{R}$ $\alpha 2 \beta 3(\mathrm{~V} 175 \mathrm{~A}) \gamma 2 \mathrm{~L}$ showed that the GABA-induced current was not potentiated by histamine concentrations up to $3 \mathrm{mM}$ (0.1 to $3 \mathrm{mM}$; Figure 5). Only the highest concentration, $10 \mathrm{mM}$, significantly changed the GABA-induced $\left(\mathrm{EC}_{16}\right)$ current, increasing it 1.4-fold (Figure 5B). In comparison to the wt (Figure 6C), the potentiation effected by histamine is drastically reduced. This suggests that V175 is involved in the action of histamine on the $\mathrm{GABA}_{\mathrm{A}}$ Rs. To demonstrate that this effect is not dependent on the presence of the $\alpha 2$ subunit, we tested the $\alpha 1 \beta 3(\mathrm{~V} 175 \mathrm{~A}) \gamma 2 \mathrm{~L}$ combination and also found a significant reduction in potentiation (Supplementary Figure S1). To ensure that the loss of potentiation is specific for histamine, we tested this mutated receptor with $10 \mu \mathrm{M}$ propofol, which caused a 1.8-fold potentiation (data not show) demonstrating that GABAinduced currents at this receptor can be potentiated by other modulators.

In the initial screening, the potentiating effect of histamine appeared to be increased at $\mathrm{GABA}_{\mathrm{A}} \mathrm{R} \alpha 2 \beta 3(\mathrm{Q} 185 \mathrm{~A}) \gamma 2 \mathrm{~L}$. The investigation of various histamine concentrations (0.01 to $10 \mathrm{mM}$ ) revealed a dose-dependent potentiation of the GABA $\left(\mathrm{EC}_{11}\right)$ response (Figures $\left.\mathbf{6 A , B}\right)$. In comparison to the wt receptor (Figure 6C), where the first significant potentiation was observed at $1 \mu \mathrm{M}$ histamine, concentrations as low as 


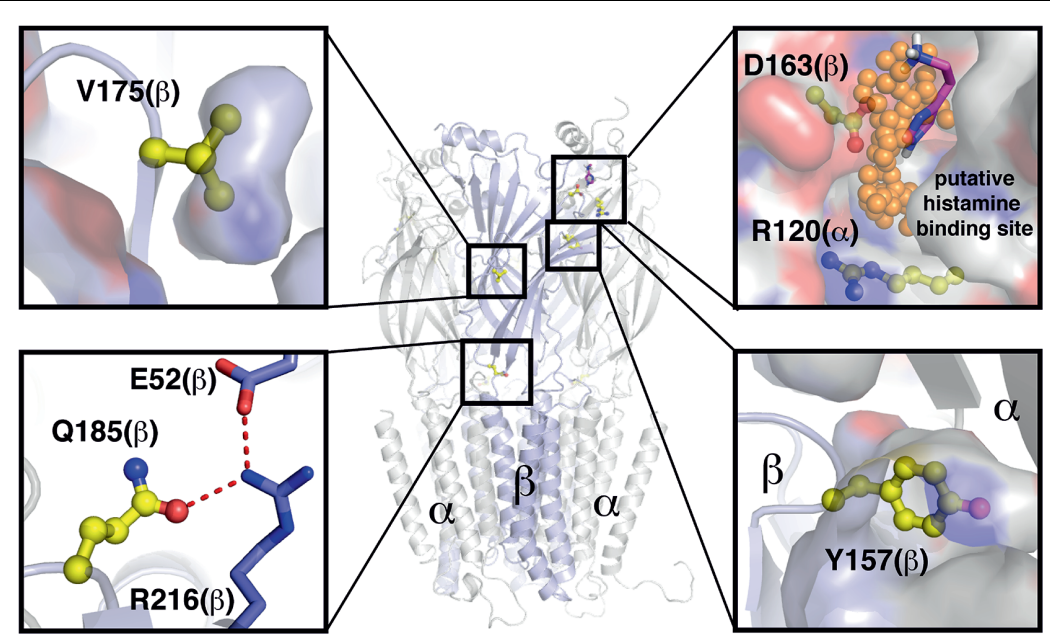

FIGURE 7 | Overview of positions and functions of mutated residues. Structural model based on PDB ID 4COF (Miller and Aricescu, 2014). Backbone displayed as cartoon, van der Waals surface as surface, selected residues as sticks, or balls and sticks, respectively. Extracellular domains visible as sheets, transmembrane domains as helical domains. Putative binding positions of small organic molecules according to TRIDOCK analysis (te Heesen et al., 2007) as orange spheres and histamine in magenta. Y157 is actively taking part in formation of the interface between the two subdomains. D163( $\beta)$ and R120( $\alpha)$ form a putative histamine binding site at the interface between subdomains $\alpha$ and $\beta$. Q185 at the interface between transmembrane and extracellular domains is part of a hydrogen bonding network with the highly conserved residues E52 and R216. The V175 side chain is buried within the extracellular subdomains, and thus important for their correct folding. None of the investigated residues except D163( $\beta$ ) and R120( $\alpha$ ) show a putative small molecule binding site.
$10 \mu \mathrm{M}$ histamine produced significant potentiation at the $\alpha 2 \beta 3(\mathrm{Q} 185 \mathrm{~A}) \gamma 2 \mathrm{~L}$ receptor. For most concentrations up to $1 \mathrm{mM}$, histamine is a significantly better potentiator at the mutated receptor (Supplementary Table S2). At higher concentrations, the effect is no longer significant, which is an indication that the potency but not the efficacy of histamine is enhanced by this mutation. To demonstrate that this effect is not dependent on the presence of the $\alpha 2$ subunit, we tested the $\alpha 1 \beta 3(\mathrm{Q} 185 \mathrm{~A}) \gamma 2 \mathrm{~L}$ subunit combination and also found a significant increase in potentiation (Supplementary Figure S1).

\section{Discussion}

Our study confirms the recent finding (Saras et al., 2008; Bianchi et al., 2011) that there is a robust modulatory effect of histamine on $\mathrm{GABA}_{\mathrm{A}}$ Rs with different subunit combinations. The screening of point mutated $\mathrm{GABA}_{\mathrm{A}} \mathrm{R}$ subunits revealed that most mutations, which encompass several amino acids conserved in $\beta$ subunits, did not influence histamine potentiation. Our results demonstrate that the point mutations $\mathrm{N} 265 \mathrm{M}$ and M286W of amino acids in the $\beta$ subunit that are important for the modulation by etomidate and propofol (Siegwart et al., 2002; Jurd et al., 2003; Reynolds et al., 2003) had no effect on the modulation of the GABA-induced current by histamine. Our results indicate that histamine does not act through these known modulation mechanisms.

In our work, we identified amino acid residues important for the modulatory action of histamine on $\mathrm{GABA}_{\mathrm{A}}$ Rs. Four amino acid residues are located on the $\beta$ subunit, consistent with the idea proposed by Saras et al. (2008) that the $\beta$ subunit is involved in the action of histamine at the $\mathrm{GABA}_{\mathrm{A}}$ Rs. Most recently, the crystal structure of the human $\$ 3$ homopentameric receptor was resolved (Miller and Aricescu, 2014). To assess the potential function of the mutated amino acids, we build a homology model of an $\alpha 1 / \beta 3$ heteropentamer (Figure 7).

The point mutation $\beta 2(\mathrm{Y} 157 \mathrm{~F})$ was only effective in receptors containing the $\gamma 2 \mathrm{~L}$ subunit and did not alter histamine's action on receptors composed solely of a and $\beta$ subunits. This indicates that histamine does not directly interact with the amino acid Y157. The presence of the $\gamma 2$ subunit alters the potentiation by histamine (Saras et al., 2008) and propofol (Siegwart et al., 2002). An indirect participation could be caused by an influence of amino acid Y157 on the interaction of $\gamma 2$ with other subunits in a heteromeric receptor. This is supported by the location of Y157 in the homology model, as it is actively taking part in formation of the interface between the two extracellular subdomains (Figure 7).

A further amino acid residue that is involved in the modulatory effect of histamine is $\beta 3(\mathrm{Q} 185)$. This amino acid has a potentially negative impact on histamine potentiation, and the Q185A mutation enhances the effect of lower concentrations of histamine on the $\mathrm{GABA}_{\mathrm{A}} \mathrm{R}$. Q185 at the interface between transmembrane and extracellular domains is part of a hydrogen bonding network with the highly conserved residues E52 and R216 (Figure 7). The amino acid V175 resides inside the extra cellular domain and is of potential structural importance (Figure 7). Therefore, the Q185A or V175A mutations influence the histamine potentiation possibly by allosteric effects and are not part of a binding site.

The two amino acid residues that we identified as possibly being directly involved in the action of histamine on the $\mathrm{GABA}_{\mathrm{A}} \mathrm{R}$ are $\mathrm{R} 120$ on the $\alpha$ subunit and D163 on the $\beta$ subunit. Amino acid R120 is conserved in all $\alpha$ subunits; therefore, our 
data could be valid for all $\alpha$ subunits. Laha and Wagner (2011) showed that these amino acids could be part of a state-dependent salt-bridge. This potential salt-bridge between R120 on the $\alpha$ subunit and D163 on the $\beta$ subunit stabilizes the binding of GABA (Laha and Wagner, 2011). Disruption of the salt-bridge on the $\alpha$ subunit by the R120A mutation greatly increases the $\mathrm{EC}_{50}$ of GABA. The D163A mutation on the $\beta$ subunit clearly reduces histamine potentiation, and histamine potentiation is nearly absent in receptors with the double mutation. Based on our homology model, these two amino acid residues are not close enough to form a salt bridge directly (Figure 7). However, the crystal structure is derived from a homopentameric receptor in a ligand bound state with the artificial agonist benzamidine. Though this benzamidine binding site is found in the vicinity of Y157 (Miller and Aricescu, 2014), it might influence the overall structure of the extracellular domain, including the position of R120. However, an analysis with TRIDOCK (te Heesen et al., 2007) revealed that a putative small molecule ligand binding site exists between D163 and R120 (Figure 7). Furthermore, our docking analysis revealed that histamine can bind in various ways at this site (see Figure 7 and Supplementary Figure 2) with a comparably low predicted binding affinity $[\Delta \mathrm{G}($ bind $)=-3.9$ to $-3.7 \mathrm{kcal} / \mathrm{mol}$ ], which is in agreement with our comparably low histamine affinities measured experimentally. At the found docking positions, the histamine ammonium headgroup interacts majorly with $\mathrm{D} 163(\beta)$, and thus probably weakens the R120/D163 interaction, which is in agreement with our experimental results. Furthermore, the docking positions found are in good agreement with the binding positions found by TRIDOCK. This position therefore could be a binding site for histamine, as well.

On the basis of our investigations, we suggest that histamine interacts with D163 on the $\beta$ subunit and weakens the interaction of D163 with R120, which could lead to enhanced or prolonged GABA binding, a left shift of the GABA $\mathrm{EC}_{50}$ and thereby to potentiation. Consequently, we propose that the amino acid D163

\section{References}

Amin, J., and Weiss, D. S. (1993). GABAA receptor needs two homologous domains of the $\beta$-subunit for activation by GABA but not by pentobarbital. Nature 366, 565-569. doi: 10.1038/366565a0

Bekkers, J. M. (1993). Enhancement by histamine of NMDA-mediated synaptic transmission in the hippocampus. Science 261, 104-106. doi: $10.1126 /$ science. 8391168

Belelli, D., and Lambert, J. J. (2005). Neurosteroids: endogenous regulators of the GABAA receptor. Nat. Rev. Neurosci. 6, 565-575. doi: 10.1038/nr n1703

Bianchi, M. T., Clark, A. G., and Fisher, J. L. (2011). The wakepromoting transmitter histamine preferentially enhances $\alpha-4$ subunit-containing GABAA receptors. Neuropharmacology 61, 747-752. doi: 10.1016/j.neuropharm.2011.05.020

Biasini, M., Bienert, S., Waterhouse, A., Arnold, K., Studer, G., Schmidt, T., et al. (2014). SWISS-MODEL: modelling protein tertiary and quaternary structure using evolutionary information. Nucleic Acids Res. 42, W252-W258. doi: 10.1093/nar/gku340

Bureau, M. H., and Olsen, R. W. (1991). Taurine acts on a subclass of GABAA receptors in mammalian brain in vitro. Eur. J. Pharmacol. 207, 9-16. doi: 10.1016/S0922-4106(05)80031-8 is essential for the modulation of $\mathrm{GABA}_{\mathrm{A}} \mathrm{Rs}$ by histamine and possibly a part of the histamine binding site. We demonstrate with our results a further function of the interaction of the $\alpha$ and $\beta$ subunit mediated by D163 with R120, which is vital for both histamine potentiation and GABA affinity. The amino acid D163 is conserved in all $\beta$ subunits of the $\mathrm{GABA}_{\mathrm{A}}$ Rs. In addition, amino acids homologous to D163 could be detected in the $\alpha 1$ subunit of the GlyR and $\alpha 7$ subunit of the nAChRs (Galzi et al., 1996; Newell et al., 2004). The homologous amino acid in the $\mathrm{nAChR}$ is involved in the change of the affinity for calcium and acetylcholine (Galzi et al., 1996).

\section{Conclusion}

Our data show that histamine's potentiation depends on amino acid D163 of the $\beta$ subunit and R120 of the $\alpha$ subunit. Interaction of these amino acids lowers the $\mathrm{EC}_{50}$ for GABA (Laha and Wagner, 2011). We propose that histamine potentiates $\mathrm{GABA}_{\mathrm{A}}$ Rs by influencing this interaction and that these amino acids are part of a potential histamine binding site.

\section{Acknowledgments}

We thank J. Gerkrath, T. Lichtleitner, and U. Müller and for excellent technical assistance. This work was funded by a grant (SFB 642) from the German Research Foundation (Deutsche Forschungsgemeinschaft) to $\mathrm{HH}$.

\section{Supplementary Material}

The Supplementary Material for this article can be found online at: http://journal.frontiersin.org/article/10.3389/fphar. 2015.00106/abstract

Chang, Y., and Weiss, D. S. (1999). Allosteric-activation mechanism of the $\alpha 1 \beta 2 \gamma 2 \gamma$-aminobutyric acid type A receptor revealed by mutation of the conserved M2 leucine. Biophys. J. 77, 2542-2551. doi: 10.1016/S00063495(99)77089-X

Congreve, M., Carr, R., Murray, C., and Jhoti, H. (2003). A rule of three for fragment- based lead discovery. Drug Discov. Today 8, 876-877. doi: 10.1016/S1359-6446(03)02831-9

Edgar, R. (2004). MUSCLE: multiple sequence alignment with high accuracy and high throughput. Nucleic Acids Res. 32, 1792-1797. doi: 10.1093/nar/ gkh340

Galzi, J. L., Bertrand, S., Corringer, P. J., Changeux, J. P., and Bertrand, D. (1996). Identification of calcium binding sites that regulate potentiation of a neuronal nicotinic acetylcholine receptor. EMBO J. 15, 5824-5832.

Grobin, A. C., Matthews, D. B., Devaud, L. L., and Morrow, A. L. (1998). The role of GABAA receptors in the acute and chronic effects of ethanol. Psychopharmacology (Berl.) 139, 2-19. doi: 10.1007/s0021300 50685

Haas, H. L., Sergeeva, O. A., and Selbach, O. (2008). Histamine in the nervous system. Physiol. Rev. 88, 1183-1241. doi: 10.1152/physrev.0004 3.2007

Heckman, K. L., and Pease, L. R. (2007). Gene splicing and mutagenesis by PCRdriven overlapextension. Nat. Protoc. 2, 924-932. doi: 10.1038/nprot.2007.132 
Hosie, A. M., Dunne, E. L., Harvey, R. J., and Smart, T. G. (2003). Zincmediated inhibition of GABAA receptors: discrete binding sites underlie subtype specificity. Nat. Neurosci. 6, 362-369. doi: 10.1038/nn1030

Jurd, R., Arras, M., Lambert, S., Drexler, B., Siegwart, R., Crestani, F., et al. (2003). General anesthetic actions in vivo strongly attenuated by a point mutation in the GABAA receptor $\beta 3$ subunit. FASEB J. 17, 250-252.

Kim, H., and McDonald, R. L. (2003). An n-terminal histidine is the primary determinant of $\alpha$ subunit-dependent $\mathrm{Cu} 2+$ sensitivity of $\alpha \beta 3 \gamma 2 \mathrm{~L}$ GABAA receptors. Mol. Pharmacol. 64, 1145-1152. doi: 10.1124/mol.64.5.1145

Kletke, O., Sergeeva, O. A., Lorenz, P., Oberland, S., Meier, J. C., Hatt, H., et al. (2013). New insights in endogenous modulation of ligand-gated ion channels: histamine is an inverse agonist at strychnine sensitive glycine receptors. Eur. J. Pharmacol. 710, 59-66. doi: 10.1016/j.ejphar.2013.04.002

Krasowski, M. D., Nishikawa, K., Nikolaeva, N., Lin, A., and Harrison, N. L. (2001). Methionine 286 in transmembrane domain 3 of the GABAA receptor $\beta$ subunit controls a binding cavity for propofol and other alkylphenol general anesthetics. Neuropharmacology 41, 952-964. doi: 10.1016/S0028-3908(01)00141-1

Kufareva, I., Rueda, M., Katritch, V., Stevens, R. C., and Abagyan, R. (2011). Status of GPCR modeling and docking as reflected by community-wide GPCR dock 2010 assessment. Structure 19, 1108-1126. doi: 10.1016/j.str.2011.05.012

Laha, K. T., and Wagner, D. A. (2011). A state-dependent salt-bridge interaction exists across the $\beta / \alpha$ intersubunit interface of the GABAA receptor. Mol. Pharmacol. 79, 662-671. doi: 10.1124/mol.110.068619

Li, G. D., Chiara, D. C., Sawyer, G. W., Husain, S. S., Olsen, R. W., and Cohen, J. B. (2006). Identification of a GABAA receptor anesthetic binding site at subunit interfaces by photolabeling with an etomidate analog. J. Neurosci. 26, 11599-11605. doi: 10.1523/JNEUROSCI.3467-06.2006

McDonald, R. L., and Olsen, R. W. (1994). GABAA receptor channels. Annu. Rev. Neurosci. 17, 569-602. doi: 10.1146/annurev.ne.17.030194.003033

Miller, P. S., and Aricescu, A. R. (2014). Crystal structure of a human GABAA receptor. Nature 512, 270-275. doi: 10.1038/nature13293

Newell, J. G., McDevitt, R. A., and Czajkowski, C. (2004). Mutation of Glutamate 155 of the GABAA Receptor $\beta 2$ subunit produces a spontaneously open channel: a trigger for channel activation. J. Neurosci. 24, 11226-11235. doi: 10.1523/JNEUROSCI.3746-04.2004

Nutt, D. (2006). GABAA receptors: subtypes, regional distribution, and function. J. Clin. Sleep Med. 2, 7-11.

Olsen, R. W., and Sieghart, W. (2008). International union of pharmacology. LXX. Subtypes of gamma-aminobutyric acid A receptors: classification on the basis of subunit composition, pharmacology, and function. Update. Pharmacol. Rev. 60, 243-260. doi: 10.1124/pr.108.00505

Pirker, S., Schwarzer, C., Wieselthaler, A., Sieghart, W., and Sperk, G. (2000). GABAA receptors: immuncytochemical distribution of 13 subunits in the adult rat brain. Neuroscience 101, 815-850. doi: 10.1016/S0306-4522(00)00442-5

Reynolds, D. S., Roshal, T. W., Cirone, J., O’Meara, G. F., Haythornthwaite, A., Newman, R. J., et al. (2003). Sedation and anesthesia mediated by distinct GABAA receptor isoforms. J. Neurosci. 23, 8608-8617.

Rudolph, U., and Knoflach, F. (2011). Beyond classical benzodiazepines: novel therapeutic potential of GABAA receptor subtypes. Nat. Rev. Drug Discov. 10, 685-697. doi: 10.1038/nrd3502

Saras, A., Gisselmann, G., Vogt-Eisele, A. K., Erlkamp, K. S., Kletke, O., Pusch, H., et al. (2008). Histamine action on vertebrate GABAA receptors; direct channel gating and potentiation of GABA responses. J. Biol. Chem. 283, 10470-10475. doi: 10.1074/jbc.M709993200

Schneider, M., Wolf, S., Schlitter, J., and Gerwert, K. (2011). The structure of active opsin as a basis for identification of GPCR agonists by dynamic homology modelling and virtual screening assays. FEBS Lett. 585, 3587-3592. doi: 10.1016/j.febslet.2011.10.027

Schrödinger, LLC. (2010). The PyMOL Molecular Graphics System, Version 1.3r1. Schuttelkopf, A. W., and van Aalten, D. M. (2004). PRODRG: a tool for high-throughput crystallography of protein-ligand complexes. Acta Crystallogr. D Biol. Crystallogr. 60, 1355-1363. doi: 10.1107/S09074449040 11679

Sergeeva, O. A., Kletke, O., Kragler, A., Poppek, A., Fleischer, W., Schubring, S. R., et al. (2010). Fragrant dioxane derivates identify $\beta 1$-subunitcontaining GABAA receptors. J. Biol. Chem. 285, 23985-23993. doi: 10.1074/jbc.M110.103309

Siegwart, R., Jurd, R., and Rudolph, U. (2002). Molecular determinants for the action of general anesthetics at recombinant $\alpha 2 \beta 3 \gamma 2 \gamma$-aminobutyric acidA receptors. J. Neurochem. 80, 140-148. doi: 10.1046/j.0022-3042.2001. 00682.x

Sigel, E., Baur, R., Kellenberger, S., and Malherbel, P. (1992). Point mutations affecting antagonist affinity and agonist dependent gating of GABAA receptor channels. EMBO J. 11, 2017-2023.

Simon, J., Wakimoto, H., Fujita, N., Lalande, M., and Barnard, E. A. (2004). Analysis of the set of GABAA receptor genes in the human genome. J. Biol. Chem. 279, 41422-41435. doi: 10.1074/jbc.M401354200

te Heesen, H. T., Schlitter, A. M., and Schlitter, J. (2007). Empirical rules facilitate the search for binding sites on protein surfaces. J. Mol. Graph. Model. 25, 671-679. doi: 10.1016/j.jmgm.2006.05.005

The UniProt Consortium. (2013). Activities at the Universal Protein Resource (UniProt). Nucleic Acids Res. 42, D191-D198. doi: 10.1093/nar/ gkt1140

Thompson, S. A., Whiting, P. J., and Wafford, K. A. (1996). Barbiturate interactions at the human GABAA receptor: dependence on receptor subunit combination. Br. J. Pharmacol. 117, 521-527. doi: 10.1111/j.1476-5381.1996.tb1 5221.x

Trott, O., and Olson, A. J. (2010). AutoDock vina: improving the speed and accuracy of docking with a new scoring function, efficient optimization, and multithreading. J. Comput. Chem. 31, 455-461.

Williams, C. A., Bell, S. V., and Jenkins, A. (2010). A residue in loop 9 of the $\beta 2$ subunit stabilizes the closed state of the GABAA receptor. J. Biol. Chem. 285, 7281-7287. doi: 10.1074/jbc.M109.050294

Wolf, S., Böckmann, M., Höweler, U., Schlitter, J., and Gerwert, K. (2008). Simulations of a $G$ protein-coupled receptor homology model predict dynamic features and a ligand binding site. FEBS Lett. 582, 3335-3342. doi: 10.1016/j.febslet.2008.08.022

Yip, G. M. S., Chen, Z. W., Edge, C. J., Smith, E. H., Dickinson, R., Hohenester, E., et al. (2013). A propofol binding site on mammalian GABAA receptors identified by photolabeling. Nat. Chem. Biol. 9, 715-720. doi: 10.1038/nchembi o. 1340

Conflict of Interest Statement: The authors declare that the research was conducted in the absence of any commercial or financial relationships that could be construed as a potential conflict of interest.

Copyright (c) 2015 Thiel, Platt, Wolf, Hatt and Gisselmann. This is an open-access article distributed under the terms of the Creative Commons Attribution License (CC BY). The use, distribution or reproduction in other forums is permitted, provided the original author(s) or licensor are credited and that the original publication in this journal is cited, in accordance with accepted academic practice. No use, distribution or reproduction is permitted which does not comply with these terms. 